\title{
Relapse of choroidal neovascularization in Bietti's crystalline retinopathy following anti-vascular endothelial growth factor therapy: A case report
}

\author{
RUI HUA ${ }^{1}$, KANG CHEN $^{1}$, YUEDONG HU $^{1}$, XINLING WANG $^{2}$ and LEI CHEN $^{1}$ \\ ${ }^{1}$ Department of Ophthalmology, First Hospital of China Medical University; ${ }^{2}$ Department of Ophthalmology, \\ Fourth Hospital of China Medical University, Shenyang, Liaoning 110001, P.R. China
}

Received September 3, 2014; Accepted July 14, 2015

DOI: $10.3892 /$ etm.2015.2716

\begin{abstract}
Choroidal neovascularization secondary to retinitis pigmentosa is rarely observed in clinical practice. The present study describes a case of atypical retinitis pigmentosa, crystalline retinal pigmentary degeneration, complicated by choroidal neovascularization (CNV) in a 26-year-old man presenting with blurred vision in the right eye. Heidelberg multimodality imaging was performed to achieve a confirmed diagnosis. Bevacizumab was injected once intravitreally. The 3-month follow-up included visualization of the lesion's regression with spectral domain optical coherence tomography (SD-OCT). However, at 3 months after the injection, the CNV reoccurred. To the best of our knowledge, this is the first time that a case of CNV secondary to retinitis pigmentosa, in which the diagnosis was confirmed via multimodality imaging and the therapeutic efficacy was evaluated by SD-OCT, has been reported in China.
\end{abstract}

\section{Introduction}

Bietti's crystalline dystrophy (BCD), first described in 1937 (1), is a rare autosomal recessive disorder characterized by crystal deposition in the retina and occasionally at the corneal limbus, followed by retinal degeneration, pigment clumping and choroidal sclerosis (2). BCD is reported to be a recessive degenerative eye disease caused by germline mutations in the CYP4V2 gene (3). $\mathrm{BCD}$ is rare in white populations but relatively common in Asian populations (3). In particular, the IVS6 to 8delTCATACAGGTCATCGCG/insGC mutation in the CYP4V2 gene is a common in Japanese patients with BCD (4). Furthermore, prevalence was $3 \%$ of nonsyndromic retinitis pigmentosa (RP) cases in $\mathrm{BCD}(5)$.

Correspondence to: Dr Rui Hua or Dr Lei Chen, Department of Ophthalmology, First Hospital of China Medical University, 155 Nanjingbei Street, Shenyang, Liaoning 110001, P.R. China

E-mail: woodshua@126.com

E-mail: leichen51@126.com

Key words: retinitis pigmentosa, choroidal neovascularization, natural history, spectral domain optical coherence tomography, intravitreal bevacizumab
The corneal deposits are detected in $\sim 33 \%$ of patients, and when corneal changes are absent the condition is termed Bietti's crystalline retinopathy $(\mathrm{BCR})(6,7)$.

$\mathrm{BCR}$ is characterized by crystal deposition in the retina, and then retinal degeneration, pigment clumping, and choroidal sclerosis but without corneal limbus changes (8). It is usually onsets in the third decade of life (9). Spectral-domain optical coherence tomography (SD-OCT) showed that most crystalline deposits in BCR were located adjacent to the inner side of the retinal pigment epithelium (RPE) layer (10).

In certain cases, choroidal neovascularization (CNV) is associated with BCR. To the best of our knowledge, there are few reports investigating the treatment of $\mathrm{BCR}$. Therefore, the present study reports a novel case of CNV in BCR treated by intravitreal bevacizumab injection, which has previously been successfully applied in the treatment of classic CNV in RP $(11,12)$.

\section{Case report}

The patient was admitted to First Hospital of China Medical University (Shenyang, China) on October 1, 2011, with no prior medical history. Informed consent was obtained from the patient. A 26-year-old man complained of blurred vision in the right eye for 2 months, with night blindness in the left and right eyes since late childhood. The patient's best-corrected visual acuity (BCVA) was 36/60 in the right eye and 60/60 in the left eye. The fundus examination revealed marked, widely distributed, crystalline degeneration in both eyes, without bony spicules. Six days after the patient's visit, foveal subretinal hemorrhage appeared in the right eye (Fig. 1). The visual field results showed impaired peripheral vision in both eyes. Afterwards, a diagnosis of BCR was determined based on the description of BCR characteristics in Chinese patients (8).

Fluorescein angiography (FA) indicated extra choroidal vessels across the posterior pole. The enhanced perifoveal hyperfluorescence in FA was diagnosed as CNV, which corresponded with the spectral domain optical coherence tomography (SD-OCT) results, whereas it was not clear in indocyanine green angiography (ICGA) (Fig. 1). Following diagnosis, bevacizumab was intravitreally injected $(1.25 \mathrm{mg} / 0.05 \mathrm{ml})$ once. In the first and fourth week after the injection, it was observed that the foveal hemorrhage had been 

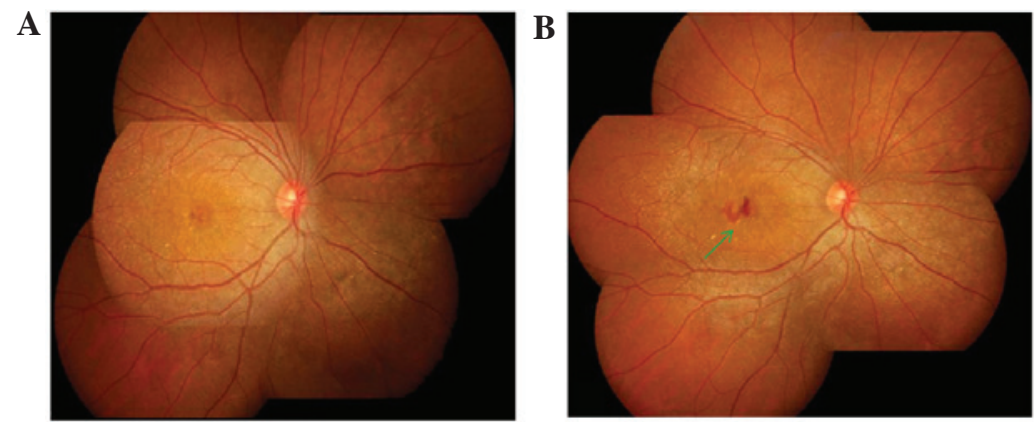

C
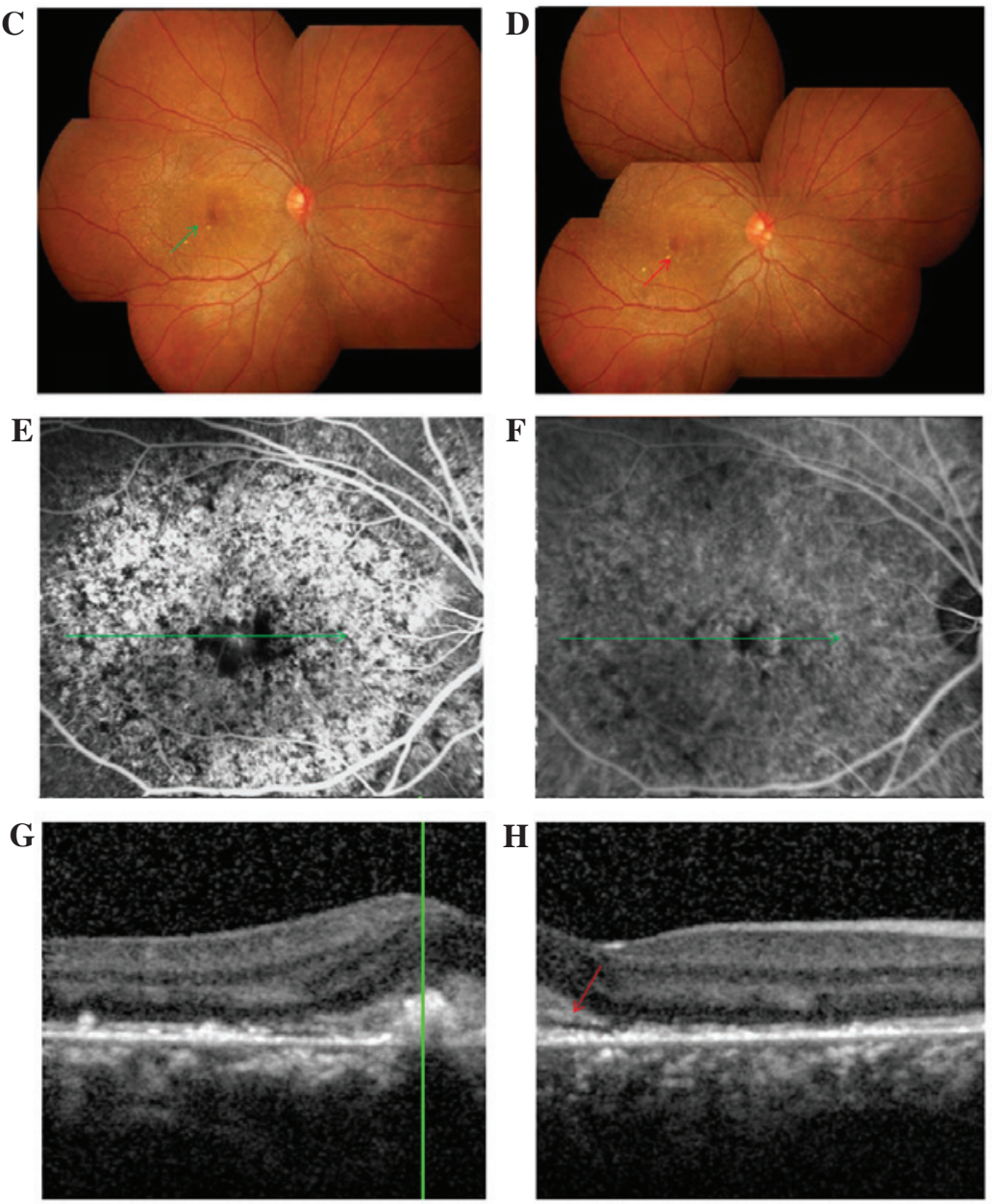

Figure 1. (A) Fundus photographs of choroidal neovascularization occurrence in the right eye. Foveal subretinal hemorrhage (green arrow) was observed (B) 6 days after the first visit of the patient and was completely absorbed (C) 1 month later. (D) Yellow-white exudates were observed 3 months later (red arrow). Compared with (E) indocyanine green angiography, the hot-spot apparent in (F) fluorescein angiography (the green arrow represents the OCT direction) was verified by (G) OCT (green line). The changes in the photoreceptors and (H) retinal pigment epithelium (red arrow) are shown. OCT, optical coherence tomography.
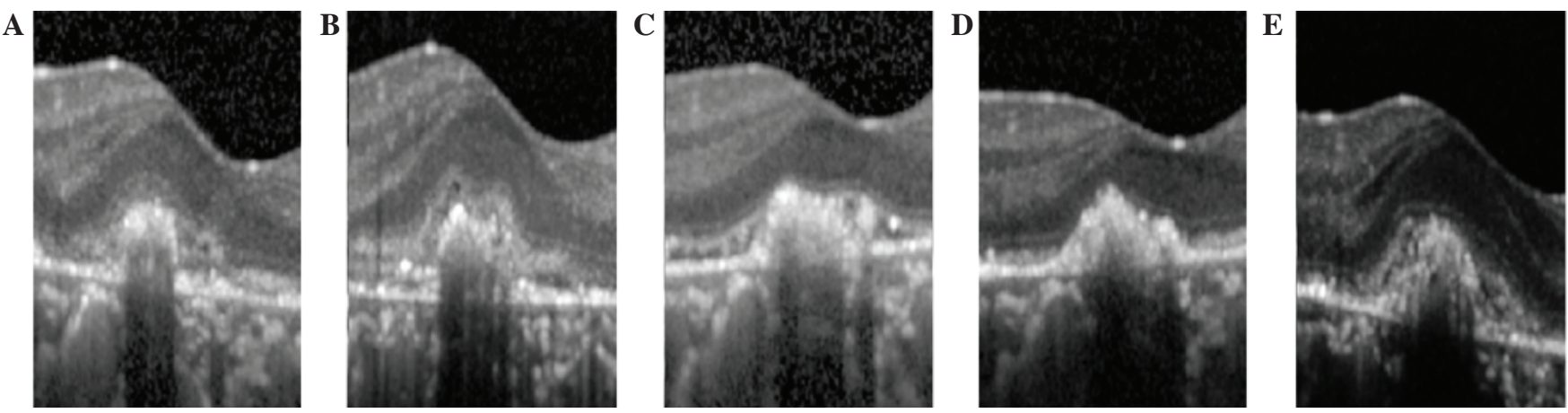

Figure 2. Progression of choroidal neovascularization. (A) Image from the patient's first visit; (B) fovea hemorrhage 6 days later; (C-E) images from (C) 1 week, (D) 1 month and (E) 3 months after intravitreal bevacizumab injection. 
gradually absorbed, and the results of SD-OCT examination showed the regression and stabilization of the CNV. The exudation between the subretinal space and CNV was absorbed completely. At 3 months after the injection, however, the CNV reoccurred (Fig. 2), with a BCVA of 48/60 in the right eye. The patient stopped attending follow-up appointments.

\section{Discussion}

The present study investigated multimodality imaging approaches for analyzing the phenotypes and treatment effects of anti-vascular endothelial growth factor (VEGF) in CNV secondary to BCR. It has been reported that visual acuity is relatively good during the early stages of $\mathrm{BCR}$, with subsequent progressive but gradual visual loss over decades due to chorioretinal atrophy (13). Intravitreal injections of anti-VEGF drugs have recently been considered to be effective in treating $\mathrm{CNV}$, by improving vision or at least halting its progressive loss (14).

We believe that the CNV in the present case was a focal minimal lesion with low activity. This is proposed on the basis that due to the young age of the patient there was a more active retinal pigment epithelial (RPE), enveloping the CNV and promoting its involution (15). Furthermore, the destruction of the choriocapillaris complex may have reduced the activity of the subretinal CNV. Fong et al (16) found that delayed choroidal filling was observed in all stages of BCR in early ICGA, as well as a relative derangement of the inner choroidal circulation, as indicated by late hypofluorescence. Finally and crucially, ICGA failed to reveal the outline of this CNV, possibly as the large indocyanine green molecule was not able to flow into the tiny vessel structure of the lesion. By contrast, due to the lack of RPE and the smaller fluorescein sodium molecule, FA is able to show a lesion of this type by enhanced perifoveal abnormal hyperfluorescence. Similarly, the exudative features of myopic CNV are more evident when observed using FA (17).

Bevacizumab is a humanized recombinant monoclonal antibody that is able to bind all VEGF subtypes, with a lower affinity, longer onset of action and reduced cost compared with ranibizumab (18). Furthermore, bevacizumab is more effective than photodynamic therapy (19). It is possible that local, tiny, low-activity CNVs are insensitive to bevacizumab. Similarly, myopic CNV with a thinner subfoveal/inferior choroid at baseline may indicate poor anatomic outcome following intravitreal anti-vascular endothelial growth factor (VEGF) treatment (20). In addition, there were other factors, such as onset age and gender, that influence the prognosis. Plafker et al (21) found that VEGF production in elderly patients may be reduced compared with younger patients, and that the aging of RPE cells may lead to impaired cellular functions including the production of cytokines such as VEGF. In addition, Wang et al (22) found that males had a higher risk of recurrence of CNV activity than females. In the present study, the subretinal CNV relapsed and exudated during the third month after treatment.

To the best of our knowledge, the present report is the first from China to describe the clinical characteristics of $\mathrm{CNV}$ in BCR and to report the efficacy of anti-VEGF therapy according to SD-OCT evaluation. Based on the present results, we propose that the CNV lesion was a local, tiny, low-activity, subretinal CNV. The observations in the present case may aid the treatment of this condition.

\section{References}

1. Gupta B, Parvizi S and Mohamed MD: Bietti crystalline dystrophy and choroidal neovascularisation. Int Ophthalmol 31: 59-61,2011.

2. Mansour AM, Uwaydat SH and Chan CC: Long-term follow-up in Bietti crystalline dystrophy. Eur J Ophthalmol 17: 680-682, 2007.

3. Nakano M, Kelly EJ, Wiek C, Hanenberg H and Rettie AE: CYP4V2 in Bietti's crystalline dystrophy: Ocular localization, metabolism of $\omega-3$-polyunsaturated fatty acids, and functional deficit of the p.H331P variant. Mol Pharmacol 82: 679-686, 2012.

4. Wada Y, Itabashi T, Sato H, Kawamura M, Tada A and Tamai M: Screening for mutations in CYP4V2 gene in Japanese patients with Bietti's crystalline corneoretinal dystrophy. Am J Ophthalmol 139: 894-899, 2005.

5. Mataftsi A, Zografos L, Millá E, Secrétan M and Munier FL: Bietti's crystalline corneoretinal dystrophy: A cross-sectional study. Retina 24: 416-426, 2004.

6. Jurklies B, Jurklies C, Schimdt U and Wessing A: Bietti's crystalline dystrophy of the retina and cornea. Retina 19: 168-171, 1999.

7. Welch R: Bietti's tapetoretinal degeneration with marginal corneal dystrophy: Crystalline retinopathy. Trans Am Ophthalmol Soc 75: 164-179, 1977

8. Liu DN, Liu Y, Meng XH and Yin ZQ: The characterization of functional disturbances in Chinese patients with Bietti's crystalline dystrophy at different fundus stages. Graefes Arch Clin Exp Ophthalmol 250: 191-200, 2012.

9. Saatci AO, Doruk HC and Yaman A: Cystoid Macular Edema in Bietti's Crystalline Retinopathy. Case Rep Ophthalmol Med 2014: 964892, 2014.

10. Kojima H, Otani A, Ogino K, Nakagawa S, Makiyama Y, Kurimoto M, Guo C and Yoshimura N: Outer retinal circular structures in patients with Bietti crystalline retinopathy. $\mathrm{Br}$ J Ophthalmol 96: 390-393, 2012.

11. Malik A, Sood S and Narang S: Successful treatment of choroidal neovascular membrane in retinitis pigmentosa with intravitreal bevacizumab. Int Ophthalmol 30: 42-58, 2010.

12. Battaglia Parodi M, Iacono P and Bandello F: Antivascular endothelial growth factor in hereditary dystrophies. Dev Ophthalmol 46: 107-110, 2010.

13. Bernauer W and Daicker B: Bietti's corneal-retinal dystrophy: A 16-year progression. Retina 12: 18-20, 1992.

14. Battaglia Parodi M, De Benedetto U, Knutsson KA, Scotti F, Librando A, Bandello F and Iacono P: Juxtafoveal choroidal neovascularization associated with retinitis pigmentosa treated with intravitreal bevacizumab. J Ocul Pharmacol Ther 28: 202-204, 2012.

15. Glaser BM, Campochiaro PA, Davis JL Jr and Jerdan JA: Retinal pigment epithelial cells release inhibitors of neovascularization. Ophthalmology 94: 780-784, 1987.

16. Fong AM, Koh A, Lee K and Ang CL: Bietti's crystalline dystrophy in Asians: Clinical, angiographic and electrophysiological characteristics. Int Ophthalmol 29: 459-470, 2009.

17. Leveziel N, Caillaux V, Bastuji-Garin S, Zmuda M and Souied EH: Angiographic and optical coherence tomography characteristics of recent myopic choroidal neovascularization. Am J Ophthalmol 155: 913-919, 2013.

18. Iu LP and Kwok AK: An update of treatment options for neovascular age-related macular degeneration. Hong Kong Med J 13: 460-470, 2007.

19. Schouten JS, La Heij EC, Webers CA, Lundqvist IJ and Hendrikse F: A systematic review on the effect of bevacizumab in exudative age-related macular degeneration. Graefes Arch Clin Exp Ophthalmol 247: 1-11, 2009

20. Ahn SJ, Woo SJ, Kim KE and Park KH: Association between choroidal morphology and anti-vascular endothelial growth factor treatment outcome in myopic choroidal neovascularization. Invest Ophthalmol Vis Sci 54: 2115-2122, 2013.

21. Plafker SM, O'Mealey GB and Szweda LI: Mechanisms for countering oxidative stress and damage in retinal pigment epithelium. Int Rev Cell Mol Biol 298: 135-177, 2012.

22. Wang H, Barteselli G, Freeman WR, Lee SN, Chhablani J, El-Emam S and Cheng L: Temporal pattern of resolution/recurrence of choroidaln neovascularization during bevacizumab therapy for wet age-related macular degeneration. Int J Ophthalmol 6: 600-605, 2013. 